MS. RITA SOUSA-SILVA (Orcid ID : 0000-0001-8640-6121)

Article type : Primary Research Articles

\title{
Tree diversity mitigates defoliation after a drought-induced tipping point
}

Running head: Tree diversity reduces defoliation by drought

Rita Sousa-Silva ${ }^{1}$, Kris Verheyen ${ }^{2}$, Quentin Ponette ${ }^{3}$, Elodie Bay ${ }^{4}$, Geert Sioen ${ }^{5}$, Hugues

Titeux $^{3}$, Thomas Van de Peer ${ }^{1}$, Koenraad Van Meerbeek ${ }^{1} \&$ Bart Muys $^{1}$

\section{Affiliations:}

${ }^{1}$ Department of Earth and Environmental Sciences, Division of Forest, Nature and

Landscape, KU Leuven, Leuven, Belgium.

${ }^{2}$ Forest \& Nature Lab, Ghent University, Gontrode-Melle, Belgium.

${ }^{3}$ Earth and Life Institute, Environmental Sciences, Université catholique de Louvain,

Louvain-la-Neuve, Belgium.

${ }^{4}$ Observatoire Wallon de la Santé des Forêts (OWSF) - Direction du Milieu forestier

(DEMNA-DMF), Service public de Wallonie (SPW), Gembloux, Belgium.

${ }^{5}$ Research Institute for Nature and Forest (INBO), Brussels, Belgium.

Correspondence may be addressed to: anarita.silva@kuleuven.be or bart.muys@kuleuven.be.

This article has been accepted for publication and undergone full peer review but has not been through the copyediting, typesetting, pagination and proofreading process, which may lead to differences between this version and the Version of Record. Please cite this article as doi: $10.1111 / \mathrm{gcb} .14326$

This article is protected by copyright. All rights reserved. 


\begin{abstract}
Understanding the processes that underlie drought-related tree vitality loss is essential for anticipating future forest dynamics, and for developing management plans aiming at increasing the resilience of forests to climate change. Forest vitality has been continuously monitored in Europe since the acid rain alert in the 1980s, and the intensive monitoring plots of ICP Forests offer the opportunity to investigate the effects of air pollution and climate change on forest condition. By making use of over 100 long-term monitoring plots, where crown defoliation has been assessed extensively since 1990, we discovered a progressive shift from a negative to a positive effect of species richness on forest health. The observed tipping point in the balance of net interactions, from competition to facilitation, has never been reported from real ecosystems outside experimental conditions; and the strong temporal consistency of our observations with increasing drought stress emphasizes its climate change relevance. Furthermore, we show that higher species diversity has reduced the severity of defoliation in the long-term. Our results confirm the greater resilience of diverse forests to future climate change-induced stress. More generally, they add to an accumulating body of evidence on the large potential of tree species mixtures to face manifold disturbances in a changing world.
\end{abstract}

\title{
Keywords
}

biodiversity | climate change | crown condition | drought stress | forest management

This article is protected by copyright. All rights reserved. 


\section{Introduction}

Disturbances are inherent to forest dynamics and contribute to forest resilience (Seidl et al., 2014). Drought, fire, insect and disease outbreaks are all predisposing factors that weaken or kill trees but at the same time can favor tree regeneration and foster diversity, pulling forests toward a shifting mosaic steady state (Bormann \& Likens, 1979). Notwithstanding this, anthropogenic climate change is likely to alter this regime in ways that can push ecosystems past tipping points (Dale et al., 2001; Millar \& Stephenson, 2015). Recently, widespread drought-induced die-off events have been observed in forests around the world (Allen et al., 2010), resulting in decreased productivity and ecosystem uptake of atmospheric carbon. For instance, the extreme drought that parched Europe in 2003 led to the lowest productivity of and carbon storage in Europe's forests during the last century (Ciais et al., 2005). This underlines the urgent need to detect, understand, and predict potential declines in the health and productivity of forest ecosystems (Trumbore et al., 2015).

Previous experimental (Williams et al., 2017) and observational (Liang et al., 2016) research has demonstrated the importance of tree species mixtures for increasing ecosystem productivity. Tree diversity has also been shown to enhance resistance to pest outbreaks (Jactel \& Brockerhoff, 2007; Guyot et al., 2016), but whether or not diverse forests are also better adapted to address drought stress is less clear. Extreme or prolonged droughts can trigger a variety of forest physiological responses, such as reduced radial growth and increased crown defoliation, potentially leading to extensive tree mortality (Carnicer et al., 2011). Some studies have reported that mixed-species forests are more resistant and resilient to drought stress (Pretzsch et al., 2013a; Gazol et al., 2016), but this is not a general pattern (Grossiord et al., 2014; Forrester et al., 2016). In fact, multiple types of interactions can occur simultaneously in mixtures, and these interactions are dynamic, changing through 
space and time (Forrester, 2014). Most studies have considered a switch in the net interactions from competition to facilitation with increasing environmental stress as primary evidence supporting the stress-gradient hypothesis (Bertness \& Callaway, 1994; Maestre et al., 2009), but few studies have considered the duration or frequency of the stress factor over time. Our analysis is, to our knowledge, the first to test the importance of species diversity for the maintenance of the health and vitality of forest ecosystems along a temporal stress gradient.

Here, we present a temporal analysis of changes in forest condition based on annual assessments of crown defoliation of beech (Fagus sylvatica L.) and sessile and pedunculate oaks (Quercus petraea (Matt.) Liebl. and Quercus robur L.). We aimed to test the influence of tree species richness on tree defoliation in relation to drought stress. We hypothesized that (i) the severity of tree defoliation increases with increasing water stress and that (ii) an increase of species richness is able to mitigate the negative impact of drought on forest vitality, mainly through the complementary use of resources. We tested these hypotheses using data from the Belgian plots of the International Co-operative Programme on Assessment and Monitoring of Air Pollution Effects on Forests (ICP Forests). ICP Forests is the largest forest monitoring network in Europe dedicated to assessing the status and development of forest condition at the European scale (Lorenz, 1995; Lorenz \& Fischer, 2013).

This article is protected by copyright. All rights reserved. 


\section{Materials and methods}

\section{Study area and crown condition assessment}

In this study, we analyzed the temporal variation in the defoliation of Fagus sylvatica (common or European beech), Quercus petraea (sessile oak), and Quercus robur (pedunculate oak). The study was carried out in Belgium using data from the European ICP Forests program. In ICP Forests, crown condition is annually assessed using harmonized methods (Eichhorn et al., 2016), which includes assessments of defoliation, damage causes and mortality as well as stem diameter. Defoliation is defined as the loss of foliage in relation to a reference tree, according to a scale with $5 \%$ intervals from 0 to $100 \%$, regardless of the cause of foliage loss. Due to the subjectivity associated with the visual assessment of defoliation (Innes et al., 1993; Ferretti, 1998), training courses are organized every year in order to ensure spatial and temporal data consistency. The annual training courses take place before commencing the field data collection, during the summer months, and the results are discussed in the field (see SM for details). Regular training courses are believed to minimize the subjectivity of the assessments and the variation among individual observers (Eickenscheidt \& Wellbrock, 2014).

The network of ICP Forests plots is organized into two levels of monitoring (Level I and Level II) (Ferretti, 2013). Level I involves large-scale monitoring of the spatial and temporal variation of forest condition. Level II aims at understanding the cause-effect relationships between the condition of forest ecosystems and stress factors. In Belgium, the Level I survey was originally conducted on a $4 \mathrm{~km} \mathrm{x} 4 \mathrm{~km}$ and $8 \mathrm{~km} \times 8 \mathrm{~km}$ grid. In each plot, a cross-cluster sampling was used to select 4 groups with 6 trees. If a monitored tree died, due to either anthropogenic or natural causes, it was replaced within the plot to ensure a continuous sample size over the time period of assessment. In 2009, circular plots (radius 18

This article is protected by copyright. All rights reserved. 
m) were installed and from 2012 on, sample trees have been selected only in these circles. Level II plots consist of a fenced core area of 0.5 ha surrounded by a $20 \mathrm{~m}$ buffer area. In the Level I network, defoliation has been assessed since 1987, whereas in the Level II network, defoliation assessments started in 1995. The initial dataset consisted of 114 Level I plots and 5 Level II plots (Table 1). Plots were selected according to the following criteria: the presence of the study species (i.e. beech or oak trees); having been assessed at least five times over the study period. Percentage of plot defoliation was estimated by averaging the values of percentage of defoliation determined for the plot trees. Only plots with a minimum of five assessed individuals per tree species were considered for the determination of defoliation at the plot level. Using the abovementioned criteria, we studied 2,710 trees during the 26-year study period, from 1990 to 2015 , resulting in a total of 37,800 observations (trees $\times$ years) available for analysis (see Table S1 for the number of plots and trees monitored in each year).

\section{Stand attributes and drought index}

In each plot, the stem diameter at $1.3 \mathrm{~m}$ was measured for all trees with diameter $\geq 7 \mathrm{~cm}$. These diameters were used to calculate the basal area $\left(\mathrm{m}^{2} \mathrm{ha}^{-1}\right)$ of each species in each plot and hence the total plot basal area (BA). Most stands (approximately 90\%) are even-aged with limited (10-year thinning cycle) or no management activity (Table 1). Species richness (SR) was determined as the number of tree species in each plot, ranging from monocultures to a maximum of five species. To avoid class imbalance, mixtures of four and five species were grouped together and a gradient of species richness with four levels was used for all the plots.

This article is protected by copyright. All rights reserved. 
Species diversity (SD) was quantified using Shannon's index, which combines both species richness and evenness, based on the basal area of each target species within a plot. It is noteworthy that not all plots were monitored since the beginning of the program, nor were they revisited every year. Hence 2011, when most of the plots (89\%) were simultaneously surveyed, was used as a reference year to describe the structure and diversity of each plot. Functional diversity (FD) was measured as functional dispersion, using leaf dry matter content (LDMC), specific leaf area (SLA) and xylem vulnerability to cavitation of the tree species present in a plot. Trait values were obtained from the TRY database (Kattge et al., 2011). FD was calculated as the mean distance of each species, weighted by its relative abundance, to the centroid of all species in a multidimensional trait space (Laliberté \& Legendre, 2010).

Climate data were obtained from the FORBIO Climate dataset. Details of the data quality procedures applied to the meteorological observations to generate this climate data set are described in Delvaux et al. (2015). Daily temperature and precipitation were summarized at monthly intervals from 1980 to 2015. Potential evapotranspiration was calculated according to Hargreaves equation (Hargreaves, 1994), using mean monthly temperature and monthly temperature range. Based on the difference between precipitation and potential evapotranspiration, we calculated the Standardized Precipitation Evapotranspiration Index (SPEI) using the SPEI-package in R (Vicente-Serrano et al., 2010). SPEI is a multi-scalar drought index that accounts for the influences of precipitation deficit and atmospheric evaporative demand on drought severity and can be used to identify water deficits and surplus conditions for a given period of time at monthly intervals. The average value of SPEI is 0 , meaning that for a certain period of time (e.g., from June to August) the climatic water balance (precipitation - potential evapotranspiration) is equal to the long-term average of the 
1980-2015 base period. Positive values indicate conditions of above-normal wet conditions, whereas negative values identify dry situations. SPEI values between 0.67 and -0.67 are considered normal, whereas values $<-0.67$ indicate drought and values $<-1.28$ indicate severe drought (Isbell et al., 2015).

Soil characteristics were retrieved from the digital soil map of Belgium (Dondeyne et al., 2014). The data set covers the two ecoregions of Belgium: the lowlands (41 plots) located to the north of the Sambre and Meuse rivers in the maritime climate zone and the uplands (78 plots) to the south of this axis, with hilly topography in the sub-continental climate zone. In the lowlands, soils are deeper $(>1 \mathrm{~m})$ and composed of silt loam and/or sand in different proportions. In the uplands, soils are shallow and can be sandy, loamy or clayey with a high stone content.

Topographic variables (terrain aspect, curvature, elevation and slope) were extracted from a LiDAR-derived digital terrain model at a spatial resolution of $1 \mathrm{~m}$ (AGIV, 2015; SPW, 2015). LiDAR point clouds were subjected to a strict geometric quality control, planimetrically $(\operatorname{RMSExy}=1 \mathrm{~m})$ and altimetrically $(\mathrm{RMSEz}=0.1 \mathrm{~m})$.

\section{Statistical analysis}

We used linear mixed-effects models to test the hypothesized relationships between tree species richness and drought effects on crown defoliation. The mean percentage of defoliation per plot per species was used as response variable (after log transformation). Since the log-transformation is not capable of handling the values $0 \%$ (not defoliated) and $100 \%$ (dead), these values were treated as 1.0 and $99.9 \%$, respectively (the value $99 \%$ was already reserved for trees that were completely defoliated but not dead). Defoliation was then 
modeled as a function of (i) species identity (accounting for variation in defoliation among species); (ii) species richness; (iii) stand basal area (to account for the effects of stem density and competition on tree defoliation), age class distribution (even-aged, uneven-aged), and management type (high forest, coppice without standards, coppice with standards); (iv) drought severity (quantified using the Standardized Precipitation Evapotranspiration Index, SPEI); (v) an interaction term between species identity, species richness, and the year of observation (to determine whether species richness effects on tree defoliation vary among species over the years); and (vi) an interaction term between species identity and SPEI (testing whether drought impacts on defoliation vary among species):

$$
\begin{aligned}
& \log \left(D F L_{i, j}\right)=\beta_{0}+\beta_{1} S P_{i}+\beta_{2} S R_{j}+\beta_{3} B A_{j}+\beta_{4} \text { Age }_{j}+\beta_{5} \text { Management }_{j}+ \\
& \beta_{6} S P E I_{j}+\beta_{8}\left[S P_{i} \times S R_{j} \times \text { Year }_{j}\right]+\beta_{9}\left[S P_{i} \times S P E I_{j}\right]+\varepsilon_{i, j}
\end{aligned}
$$

where $D F L_{i j}$ is the defoliation of species $i$ in plot $j$; $S P$ is a categorical variable encoding for the identity of species $i$ in plot $j ; S R_{j}$ is the species richness of plot $j ; B A_{j}, A g e_{j}$ and Management $t_{j}$ are, respectively, the stand basal area, the stand age structure and their management type; $S P E I_{j}$ is a measure of drought in plot $j ; Y e a r_{i}$ is a continuous variable and is interpreted as the underlying annual change in defoliation rate during the study period within each of the $j$ plots; $\beta_{0}-\beta_{9}$ are parameters to be estimated from the data (i.e., intercept and slope coefficients); and $\varepsilon_{i}$ is the residual error.

In all models, plot identity and plot cluster were included as random factors to account for the nested structure of the data (several trees located within each plot, which are themselves clustered together within known forest management units). Plot cluster is a categorical 
grouping variable that has four levels, used to identify the more or less homogeneous clusters of plots with respect to who carried out the assessment of crown condition (survey teams). Hence, this variable also accounts for systematic differences between the two levels of the monitoring network (Level I and Level II) and differences within the network of plots in Belgium (Flanders and Wallonia). To address the potential temporal autocorrelation in the data, we specified an autoregressive correlation structure [ARMA $(2,0)]$, by inspecting the autocorrelation function (ACF) of the residuals (Zuur et al., 2009). We also fit models in which we accounted for a number of confounding factors that could conceivably alter the response of trees to mixing and drought (precipitation, minimum and maximum temperature during the growing season, soil type and topography), with effectively no change in the findings (see Table S2 for a full list of models that were compared). Additionally, we fitted models that included species diversity and functional diversity indices as factors in the model. As these models yielded a worse fit to the data, but led to similar results, we focused on the parameter estimates obtained from the model including species richness.

We started by fitting a null model (i.e., an intercept-only model) and then observed how progressively increasing model complexity, by adding each predictor in turn, affected AIC values (Table S2). Model selection was then done by ranking the models by their AICc (Akaike's Information Criterion with small sample size correction), and the AICc weight (wAICc), which varies from 0 (no support) to 1 (complete support). Goodness of fit was estimated using marginal and conditional $R^{2}$, which allow for assessing the predictive capacity of mixed-effects models (Nakagawa \& Schielzeth, 2013).

This article is protected by copyright. All rights reserved. 
Analyses were conducted in R 3.4.3 (R Development Core Team, 2017), using the following libraries: vegan (Oksanen et al., 2017), lme4 (Bates et al., 2015), lmerTest (Kuznetsova et al., 2016), nlme (Pinheiro et al., 2018), and MuMIn (Barton, 2016). The predicted interactions were plotted using the sjPlot package (Lüdecke, 2016).

\section{Results}

\section{Crown defoliation and drought stress}

An increasing trend in defoliation was observed over the period 1990-2015 in the forest stands studied (Fig. 1). The overall upward trend was particularly pronounced at the end of the period of assessment. The increase in defoliation was statistically significant for all three species examined $(P<0.001)$, with peak values occurring in 2012 for $Q$. petraea and $Q$. robur and in 2014 for F. sylvatica. Another yet smaller peak is evident between 2003 and 2005, likely connected with the dry hot summer of 2003.

Next, we tested the occurrence and magnitude of drought effects using the multiscalar SPEI metric (Vicente-Serrano et al., 2010). We observed a significant increase in the number of dry years since 1980, as well as an increase in the frequency of months classified as moderate or extreme drought events (Fig. 2). Considering the possible lag in the response of tree defoliation to drought (Anderegg et al., 2013; Vicente-Serrano et al., 2013), we carried out a correlation analysis between the annual mean defoliation at plot level and the SPEI calculated at time scales between 1 and 24 months for the months prior to the survey (crown condition surveys are carried out every year in July and August). In this study, the highest correlations were found for the months of March, April and May for SPEI scales longer than 12 months, spanning nearly 2 years (Fig. S1). The relationship between crown defoliation and SPEI reached the strongest negative correlation by May and when accounting for the water balance 
of the previous 21 months (hereafter $\mathrm{SPEI}_{21-\mathrm{May}}$ ). This correlation was weak but significant ( $r$ $=-0.15, P<0.001 ;$ Fig. S1).

\section{Diversity effects on drought-induced defoliation}

Species interactions are dynamic and can change through time. Accordingly, we examined the temporal pattern of defoliation along the tree species richness gradient present in the data (Fig. 3). Our results show that, at the beginning of the study period, defoliation levels were significantly higher in mixtures than in pure stands. However, this trend has progressively shifted towards lower defoliation levels at higher species richness levels. The turning point occurred around the year 2010, following a period of steady increase in defoliation. For example, the average of annual values increased from $16 \%$ in 2008 to $31 \%$ in 2012 . Furthermore, before 2010, the average defoliation in monocultures ( $\mathrm{SR}=1 ; N=38$ plots) was $15 \%$, whereas in mixtures ( $\mathrm{SR} \geq 4 ; N=16$ ) was $18 \%$. After 2010 , the average defoliation in monocultures rose to $26 \%$, whereas in mixtures this dropped to $19 \%$. This pattern is consistent among the three studied species, with minor differences in the timing and magnitude of the shift (Fig. S2).

To further quantify the factors associated with the observed patterns of defoliation, we modeled crown defoliation as a function of tree species richness and drought stress from 1990-2015 (Table 2). Including stand-level variables as covariates in the regression model, such as the stand basal area, age class distribution and the type of management, improved the variance explained (see AIC values in Table S2), though not all of them reached statistical significance. This may reflect the homogeneity of management practices, or lack of them, among the study plots at both temporal and spatial level (see Supplementary Note 1 for a discussion on the role of age). Conversely, both species richness and species identity were 
found to be significant predictors of crown defoliation $(P<0.05)$. The severity of defoliation may thus depend on the identity of the tree species concerned, including its competitive ability and drought tolerance. Additionally, the effect of drought on crown defoliation differed substantially between the three species (i.e., interaction between species identity and $\left.\mathrm{SPEI}_{21-\mathrm{May}}\right)$. For $F$. sylvatica and $Q$. petraea, the mean defoliation level is, respectively, $38 \%$ and 39\% higher following dry years than wet years (Fig. 4a). These differences are statistically significant $(P<0.001)$. The highest average defoliation was found in trees of $Q$. robur in both monocultures and mixtures. For $F$. sylvatica and $Q$. petraea, the overall increase in defoliation level during the study period was markedly more pronounced in the low-diversity plots $(\mathrm{SR} \leq 2)$ than in high-diversity plots $(\mathrm{SR} \geq 3)$ (Fig. $4 b)$.

\section{Discussion}

\section{Drought stress as a trigger for increased levels of defoliation}

Crown defoliation has been found to vary considerably across species and environments (Michel \& Seidling, 2017). Furthermore, the visual assessment of tree defoliation is susceptible to a number of different sources of error, e.g. observer bias, which could influence the reliability of the results (Ferretti, 1998). To counteract this limitation, regular training courses and quality assurance and control procedures have been progressively implemented (in Belgium as elsewhere) to improve the quality of the data and maximize the temporal and spatial comparability of results (see Bussotti et al.(2009) and Eickenscheidt \& Wellbrock (2014) for examples of these). In the present study, we observed an increasing trend in defoliation over the period of assessment, which coincides with the trend observed in other European countries, especially in southern Europe (Carnicer et al., 2011; de la Cruz et al., 2014; Bussotti et al., 2018). As such, although we cannot completely rule out the 
possibility of bias due to subjectivity in the visual assessment, these long-term trends are unlikely to be due to the effects of observer errors in assessed defoliation data.

Among the biotic and abiotic factors that drive forest defoliation, water availability is often the most limiting factor in many forest ecosystems (Bréda et al., 2006). Drought is a natural phenomenon characterized by the prevalence of low water availability during longer periods as a consequence of reduced precipitation, increased atmospheric evaporative demand or both (Trenberth et al., 2013). There is growing evidence that drought impacts have increased considerably in recent decades (Schwalm et al., 2017). In addition, projected changes in both precipitation and temperature over the 21 st century suggest a general decrease in available water for the summer period, in Belgium (Tabari et al., 2015), as elsewhere (Dai, 2012; Kumar et al., 2014), which implies that many forests will become increasingly vulnerable to drought and associated disturbances (Allen et al., 2010; Choat et al., 2012; Neumann et al., 2017). For Belgium, for instance, the cumulative water shortage during the summer season is projected to go up to about $200 \mathrm{~mm}$ in the late 21st century, suggesting an increased risk of summer drought (Tabari et al., 2015). Drought induces short-term physiological disorders by decreasing carbon and nutrient assimilation and can cause hydraulic failure (xylem embolism) in more extreme cases or carbon starvation (exhaustion of stored soluble carbohydrates in sapwood) after long exposure (Bréda et al., 2006). Trees may recover from these symptoms and restore their crowns, but in the long term, the accumulation of these processes is more likely to result in progressive decline and eventual death of the tree. Such lagged susceptibility has been widely reported (Bréda et al., 2006; Anderegg et al., 2013; Camarero et al., 2015). Anderegg et al. (2013), for example, found that hydraulic damage persisted and increased in dying trees over multiple years and exhibited few signs of repair. 
Here, based on the SPEI index, representing drought conditions in the previous 16 months, we observed a significant increase in the number of dry years, as well as a decrease in the occurrence of wet years, obviously important to restore ecosystem health after dry periods. For instance, the year with the lowest SPEI values was 1997. Yet, it was followed by relatively wet years, which are likely to have alleviated the adverse effects of drought stress on trees, thus not causing serious damage. Conversely, 2004 (which reflects the exceptional 2003 summer drought) marked the beginning of a period of successive relatively dry years, including 2005, where we observed a peak in defoliation. Such repeated drought events suggest that the studied stands may suffer chronic stress, making it plausible to conclude that the observed increase in defoliation was triggered by successive droughts. Our results correlate well with the literature in the sense that shorter drought recovery times have been shown to cause lasting damage to forests (Schwalm et al., 2017). Furthermore, we found that the highest correlations between the SPEI and tree defoliation occur at timescales longer than 12 months. These results are consistent with those of previous studies, which have observed that tree vitality in Europe's forests is substantially driven by climate variability in both the current and preceding years (Neumann et al., 2017). Defoliation of beech in a given year, for instance, has been consistently associated with low precipitation and high evapotranspiration rates in the year before (e.g., Seidling, 2007; de la Cruz et al., 2014; Ferretti et al., 2014). The previous year's defoliation has also been suggested to enhance the process of defoliation in the current year (Ferretti et al., 2007; de la Cruz et al., 2014).

\section{Tree species richness increases resistance to drought}

In mixed forests, interactions between species strongly influence ecosystem properties. Positive biodiversity-ecosystem functioning relationships are commonly attributed to a combination of selection and complementarity effects (Loreau \& Hector, 2001; Hooper et al., 
2005). In contrast, a negative effect of diversity on ecosystem functioning can result from direct competition for resources between species when ecological niches overlap (Naeem, 1998). Among the many studies that have investigated these processes, several have reported conflicting results (Jactel \& Brockerhoff, 2007; Pretzsch et al., 2013a; Jucker et al., 2014; Forrester et al., 2016). This apparent incongruence can at least partially be explained by the facts that facilitation and competition always occur simultaneously and that the net effect is strongly species- and context-dependent and subject to change through time. Such context dependency derives in part from changes in the availability of resources, and the dissimilarity in both species composition and species interactions, over space and time. These dynamics may also help to explain why the models retained large portions of unexplained variability. As for the influence of age on defoliation, there is a tendency for increased defoliation with age, but both young and older trees showed similar responses with respect to species richness (see Supplementary Note 1 for a detailed discussion).

Our results suggest that not only species interactions may involve a complex balance of competition and facilitation, but also demonstrate a complex interplay between tree species richness and the longer-term responses of forest ecosystems to drought-induced stress. Initially, defoliation levels were significantly lower in monoculture stands. However, following a progressive shift, the balance between tree species diversity and drought responses was reversed by approximately 2010, after which defoliation decreased with increasing tree species richness. While the positive effect of diversity on the vitality of young experimental tree plantations has been previously demonstrated (Van de Peer et al., 2016), our findings highlight for the first time the close link between species richness and repeated defoliation in a large systematic sample of mature (managed and unmanaged) forests. Regarding the role of management, it has been suggested that forest management can be used

This article is protected by copyright. All rights reserved. 
to reduce the incidence of defoliation, in particular caused by insects (Muzika \& Liebhold, 2000; Jactel et al., 2009). This can be done, for instance, by selectively harvesting high-risk trees to reduce the susceptibility (likelihood of defoliation) and vulnerability (likelihood of mortality following defoliation) of the stand. Thinning also modifies the structure of forest stands, and reducing stand density through silvicultural thinning has been proposed as a strategy for improving resistance and resilience to drought via increased soil water availability (D'Amato et al., 2013). In our case, however, as many plots have not been subjected to thinning or other management since the beginning of the 1990s, or when thinning has been applied, we have no indication that treatments were different between monocultures and mixtures, nor did it change over time, the management effect seems highly unlikely as an explanation of our observations. The observed tipping point in the relationship between species richness and the health and vitality of forests, suggesting that species interactions shifted from competition to facilitation, though implicit in the literature, has never been reported from real ecosystems outside experimental conditions. Furthermore, the strong temporal consistency of our observations with increasing drought stress emphasizes its climate change relevance. Natural systems are variable not only in space but also in time. However, due to the lack of long-term studies, empirical evidence for temporal shifts in the balance between facilitation and competition in long-lived systems is extremely limited (but see (Tielbörger \& Kadmon, 2000). Here, we show that this relationship is not immutable and can even flip from overperforming monocultures to overperforming mixtures with increasing environmental stress, as more diverse communities are able to maintain relatively higher levels of functioning than less diverse ones under stressful conditions (Isbell et al., 2011).

This article is protected by copyright. All rights reserved. 


\section{Mechanisms of resistance of mixtures to water stress}

The fact that, for both beech and sessile oak, the mean defoliation level was highest after dry years than wet years confirms the results of earlier studies (e.g., Seidling, 2007; Carnicer et al., 2011; Sánchez-Salguero et al., 2016), as well as our hypothesis, that drought can trigger and expedite defoliation in deciduous forests. But perhaps more importantly, our results reveal that the negative impact of drought on the crown defoliation of the three studied species in deciduous temperate forests was mitigated by species mixing through time (i.e., interaction between species richness and year of observation; Fig. 4b). This was particularly evident in F. sylvatica and Q. petraea. In the fullness of time (i.e., within the study period), the two species experienced the largest decline in vitality when growing in a monoculture (Fig. 4b), which was further corroborated by the observed shift in the relationship between tree species richness and crown defoliation. It is also noteworthy that the positive effect of species richness on crown condition arose after a period of steady increase in defoliation, which adds further support to our observation that increased stress had a stronger negative effect on less diverse plots.

This positive relationship between biodiversity and stability is often assumed to result from compensatory dynamics between species, mostly through strong complementarity between species (Morin et al., 2011). The superior performance (i.e., lower defoliation levels) of monocultures compared to stands with higher species richness at the beginning of the monitoring period might be explained by differences in resource use efficiency. On the one hand, with high resource availability, and in the absence of significant disturbances, interspecific competition might outweigh the positive effects of species facilitation and complementarity (Maestre et al., 2009); thus, this might enhance the performance of trees 
growing in monocultures. On the other hand, in the short-term, drought may cause trees in a mixed forest to compete more fiercely for resources, leaving less room for complementarity and causing positive diversity effects to weaken (Jucker et al., 2014). However, as we have shown here, under increasing environmental stress, increasing species richness reduced drought-induced defoliation in the long term. The overall pattern we found corroborates the stress-gradient hypothesis (Bertness \& Callaway, 1994; Maestre et al., 2009), which posits that the net outcome of biotic interactions (facilitation and competition) shifts from negative to positive along gradients of increasing stress. Recurrent drought periods, such as those observed in recent years, may produce a rapid loss of resilience by carbon starvation and embolism, particularly when new disturbances occur before the reserves are fully recovered (Bréda et al., 2006). Conversely, increasing tree species diversity may mitigate the impact of disturbances, as more complementary interactions are expected. Water uptake efficiency likely increases in mixed forests because a greater volume of soil can be exploited in space and time by species with complementary root stratification (Brassard et al., 2013). This can arise from root plasticity or differences in root foraging strategies among species. For example, in dry years, available water might be better used in mixed stands due to facilitation mechanisms such as hydraulic lift whereby deeper rooting tree species take up water and redistribute it via their root system to drier superficial soil layers, thus favoring shallower rooting species (Pretzsch et al., 2013a, 2013b). Resistance to insect defoliators has also been reported to be positively affected by tree species richness (Guyot et al., 2016).

In addition, previous studies have also described strong species identity effects on crown defoliation (e.g., Pollastrini et al., 2016; Bussotti et al., 2018). Thus, identity and diversity may affect tree defoliation. Surprisingly, among the three studied tree species, Q. robur exhibited the highest average defoliation in both pure and mixed stands. Pedunculate oak is 
known to be less tolerant of water shortages than sessile oak (Pretzsch et al., 2013b). However, oak is believed to suffer less than beech, partly because oak can maintain photosynthesis at low water potential (Raftoyannis \& Radoglou, 2002). This somewhat unexpected finding can, at least to some extent, be linked with the widespread occurrence of oak decline across Europe. Oak decline is a slow-acting disease complex in which several damaging agents interact and result in the mortality of oaks (Thomas et al., 2002). Both oak species are subject to decline, but on average, here and in other studies, $Q$. robur has been more severely affected than $Q$. petraea (Thomas et al., 2002). These examples may show that the current process of pedunculate oak decline is not necessarily triggered by drought, but risk is associated with increased stress. In this study, identifiable causes of defoliation and damage symptoms (as assessed according to the ICP Forests criteria) were not consistently available for analysis or were unreliable. Future research that examine particular causes of stem and crown damages, and their influence on crown condition, may provide valuable information to disentangle the cause-effect relationship of forest decline.

To conclude, we found that the crown condition of beech and oak trees in temperate deciduous forests has deteriorated over the past quarter century, closely connected to increasing drought stress. This change has triggered a regime shift from healthy monocultures to resilient tree species mixtures. For the first time, we document a tipping point beyond which a drought stress-induced positive diversity-stability relationship in mature forest ecosystems emerged. Our results show that standardized, large-scale, long-term monitoring of forest health, such as that performed in Europe by ICP Forests, is an effective method to detect climate change-induced and tree diversity-mediated trends in forest vitality. Despite repeated criticism due to subjectivity in the visual assessment and a number of limitations have been associated with the monitoring approach (Innes et al., 1993; Ferretti \& Chiarucci, 
2003), the very high representativeness over space and time of the ICP Forests monitoring program, and the continuous improvement in the quality of data that has been achieved so far (Bussotti et al., 2009; Eickenscheidt \& Wellbrock, 2014), has proven to be an effort that merits improved and extended continuation. We recommend further investigation of longitudinal data sets of forest vitality to corroborate the trends we observed for other species and in different climatological contexts.

\section{Acknowledgments}

This research was funded through the FORBIO Climate project by the Belgian Federal Science Policy Office (BELSPO; BR/132/A1/FORBIO Climate). We thank Christian Laurent (Department of Nature and Forests of the Walloon Public Service) for providing data from Wallonia, and all people involved in the collection of the vast quantity of data in the ICP Forests network in Belgium. We also thank Stefaan Dondeyne and Jennifer Roelens for their assistance with soil characterization and DEMs derived topography metrics. We are grateful to anonymous referees for their helpful comments on earlier versions of this manuscript.

\section{References}

Allen CD, Macalady AK, Chenchouni H et al. (2010) A global overview of drought and heatinduced tree mortality reveals emerging climate change risks for forests. Forest Ecology and Management, 259, 660-684.

Anderegg WRL, Plavcová L, Anderegg LDL, Hacke UG, Berry JA, Field CB (2013) Drought's legacy: Multiyear hydraulic deterioration underlies widespread aspen forest die-off and portends increased future risk. Global Change Biology, 19, 1188-1196.

This article is protected by copyright. All rights reserved. 
Barton K (2016) MuMIn: Multi-Model Inference.

Bates D, Mächler M, Bolker B, Walker S (2015) Fitting Linear Mixed-Effects Models Using Ime4. Journal of Statistical Software, 67, 1-48.

Bertness MD, Callaway R (1994) Positive interactions in communities. Trends in Ecology \& Evolution, 9, 191-193.

Bormann FH, Likens GE (1979) Pattern and process in a forested ecosystem: disturbance, development and the steady state based on the Hubbard Brook ecosystem. Springer, New York, 272 pp.

Brassard BW, Chen HYH, Cavard X et al. (2013) Tree species diversity increases fine root productivity through increased soil volume filling (ed Chen H). Journal of Ecology, 101, 210-219.

Bréda N, Huc R, Granier A, Dreyer E (2006) Temperate forest trees and stands under severe drought: a review of ecophysiological responses, adaptation processes and long-term consequences. Annals of Forest Science, 63, 625-644.

Bussotti F, Cozzi A, Cenni E, Bettini D, Sarti C, Ferretti M (2009) Quality Assurance and measurement errors in monitoring tree crown conditions in Italy. Journal of environmental monitoring : JEM, 11, 769-73.

Bussotti F, Feducci M, Iacopetti G, Maggino F, Pollastrini M, Selvi F (2018) Linking forest diversity and tree health: preliminary insights from a large-scale survey in Italy. Forest Ecosystems, 5, 12.

Camarero JJ, Gazol A, Sangüesa-Barreda G, Oliva J, Vicente-Serrano SM (2015) To die or not to die: Early warnings of tree dieback in response to a severe drought (ed Gibson D). Journal of Ecology, 103, 44-57.

Carnicer J, Coll M, Ninyerola M, Pons X, Sánchez G, Peñuelas J (2011) Widespread crown condition decline, food web disruption, and amplified tree mortality with increased climate change-type drought. Proceedings of the National Academy of Sciences of the United States of America, 108, 1474-8.

Choat B, Jansen S, Brodribb TJ et al. (2012) Global convergence in the vulnerability of forests to drought. Nature, 491, 752.

This article is protected by copyright. All rights reserved. 
Ciais P, Reichstein M, Viovy N et al. (2005) Europe-wide reduction in primary productivity caused by the heat and drought in 2003. Nature, 437, 529-533.

D'Amato AW, Bradford JB, Fraver S, Palik BJ (2013) Effects of thinning on drought vulnerability and climate response in north temperate forest ecosystems. Ecological Applications, 23, 1735-1742.

Dai A (2012) Increasing drought under global warming in observations and models. Nature Climate Change, 3, 52-58.

Dale V, Joyce L, McNulty S, Neilson R (2001) Climate change and forest disturbances: climate change can affect forests by altering the frequency, intensity, duration, and timing of fire, drought, introduced species,. BioScience.

Eichhorn J, Roskams P, Potocic N et al. (2016) Part IV: Visual Assessment o f Crown Condition and Damaging Agents. In: Manual on methods and criteria for harmonized sampling, assessment, monitoring and analysis of the effects of air pollution on forests (ed UNECE ICP Forests Programme Co-ordinating Centre), p. 54. Thünen Institute of Forest Ecosystems, Eberswalde, Germany.

Eickenscheidt N, Wellbrock N (2014) Consistency of defoliation data of the national training courses for the forest condition survey in Germany from 1992 to 2012. Environmental Monitoring and Assessment, 186, 257-275.

Ferretti M (1998) Potential and limitation of visual indices of tree condition. In: Chemosphere, Vol. 36, pp. 1031-1036. Pergamon.

Ferretti M (2013) Concepts and Design Principles Adopted in the International Cooperative Program on the Assessment and Monitoring of Air Pollution Effects on Forests (ICP Forests). In: Forest Monitoring - Methods for terrestrial investigations in Europe with an overview of North America and Asia, Vol. 12 (eds Ferretti M, Fischer R), pp. 91-104. Elsevier, London.

Ferretti M, Chiarucci A (2003) Design concepts adopted in long-term forest monitoring programs in Europe - Problems for the future? Science of the Total Environment, 310, $171-178$.

Ferretti M, Calderisi M, Bussotti F (2007) Ozone exposure, defoliation of beech (Fagus 
sylvatica L.) and visible foliar symptoms on native plants in selected plots of SouthWestern Europe. Environmental Pollution, 145, 644-651.

Ferretti M, Nicolas M, Bacaro G et al. (2014) Plot-scale modelling to detect size, extent, and correlates of changes in tree defoliation in French high forests. Forest Ecology and Management, 311, 56-69.

Forrester DI (2014) The spatial and temporal dynamics of species interactions in mixedspecies forests: From pattern to process. Forest Ecology and Management, 312, 282292.

Forrester DI, Bonal D, Dawud S, Gessler A, Granier A, Pollastrini M, Grossiord C (2016) Drought responses by individual tree species are not often correlated with tree species diversity in European forests (ed Finn J). Journal of Applied Ecology, 53, 1725-1734.

Gazol A, Camarero JJ, Gomez-Aparicio L (2016) Functional diversity enhances silver fir growth resilience to an extreme drought (ed Gomez-Aparicio L). Journal of Ecology, 104, 1063-1075.

Grossiord C, Granier A, Ratcliffe S et al. (2014) Tree diversity does not always improve resistance of forest ecosystems to drought. Proceedings of the National Academy of Sciences, 111, 14812-14815.

Guyot V, Castagneyrol B, Vialatte A et al. (2016) Tree diversity reduces pest damage in mature forests across Europe. Biology Letters, 12, 1146-1156.

Hooper DU, Chapin FS, Ewel JJ et al. (2005) Effects of biodiversity on ecosystem functioning: A consensus of current knowledge. Ecological Monographs, 75, 3-35.

Innes JL, Landmann G, Mettendorf B (1993) Consistency of observations of forest tree defoliation in three European countries. Environmental Monitoring and Assessment, 25, $29-40$.

Isbell F, Calcagno V, Hector A et al. (2011) High plant diversity is needed to maintain ecosystem services. Nature, 477, 199-202.

Jactel H, Brockerhoff EG (2007) Tree diversity reduces herbivory by forest insects. Ecology Letters, 10, 835-48.

This article is protected by copyright. All rights reserved. 
Jactel H, Nicoll BC, Branco M et al. (2009) The influences of forest stand management on biotic and abiotic risks of damage. Annals of Forest Science, 66, 701-701.

Jucker T, Bouriaud O, Avacaritei D, Dănilă I, Duduman G, Valladares F, Coomes DA (2014) Competition for light and water play contrasting roles in driving diversity-productivity relationships in Iberian forests. Journal of Ecology, 102, 1202-1213.

Kumar S, Lawrence DM, Dirmeyer PA, Sheffield J (2014) Less reliable water availability in the 21 st century climate projections. Earth's Future, 2, 152-160.

Kuznetsova A, Bruun Brockhoff P, Haubo Bojesen Christensen R (2016) lmerTest: Tests in Linear Mixed Effects Models.

de la Cruz AC, Gil PM, Fernández-Cancio Á, Minaya M, Navarro-Cerrillo RM, SánchezSalguero R, Grau JM (2014) Defoliation triggered by climate induced effects in Spanish ICP Forests monitoring plots. Forest Ecology and Management, 331, 245-255.

Liang J, Crowther TW, Picard N et al. (2016) Positive biodiversity-productivity relationship predominant in global forests. Science, 354, aaf8957-aaf8957.

Loreau M, Hector A (2001) Partitioning selection and complementarity in biodiversity experiments. Nature, 412, 72-76.

Lorenz M (1995) International Co-operative Programme on Assessment and Monitoring of Air Pollution Effects on Forests-ICP Forests-. Water, Air, and Soil Pollution, 85, 12211226.

Lorenz M, Fischer R (2013) Pan-European Forest Monitoring: An Overview. Developments in Environmental Science, 12, 19-32.

Lüdecke D (2016) sjPlot: Data Visualization for Statistics in Social Science.

Maestre FT, Callaway RM, Valladares F, Lortie CJ (2009) Refining the stress-gradient hypothesis for competition and facilitation in plant communities. Journal of Ecology, 97, 199-205.

Michel A, Seidling W (2017) Forest Condition in Europe: 2017 Technical Report of ICP Forests. Report under the UNECE Convention on Long-Range Transboundary Air Pollution (CLRTAP). BFW-Dokumentation 24/2017. Vienna: BFW Austrian Research 
Centre for Forests, 128 pp.

Millar CI, Stephenson NL (2015) Temperate forest health in an era of emerging megadisturbance. Science, 349, 823-826.

Morin X, Fahse L, Scherer-Lorenzen M, Bugmann H (2011) Tree species richness promotes productivity in temperate forests through strong complementarity between species. Ecology Letters, 14, 1211-1219.

Muzika RM, Liebhold AM (2000) A critique of silvicultural approaches to managing defoliating insects in North America. Agricultural and Forest Entomology, 2, 97-105.

Naeem S (1998) Species redundancy and ecossystem reliability. Conserv. Biol., 12, 39-45.

Nakagawa S, Schielzeth H (2013) A general and simple method for obtaining R2 from generalized linear mixed-effects models (ed O'Hara RB). Methods in Ecology and Evolution, 4, 133-142.

Neumann M, Mues V, Moreno A, Hasenauer H, Seidl R (2017) Climate variability drives recent tree mortality in Europe. Global Change Biology.

Oksanen J, Blanchet FG, Friendly M et al. (2017) vegan: Community Ecology Package.

Van de Peer T, Verheyen K, Baeten L, Ponette Q, Muys B (2016) Biodiversity as insurance for sapling survival in experimental tree plantations (ed Firn J). Journal of Applied Ecology, 53, 1777-1786.

Pinheiro J, Bates D, DebRoy S, Sarkar D, R Core Team (2018) nlme: Linear and Nonlinear Mixed Effects Models.

Pollastrini M, Feducci M, Bonal D et al. (2016) Physiological significance of forest tree defoliation: Results from a survey in a mixed forest in Tuscany (central Italy). Forest Ecology and Management, 361, 170-178.

Pretzsch H, Schütze G, Uhl E (2013a) Resistance of European tree species to drought stress in mixed versus pure forests: Evidence of stress release by inter-specific facilitation. Plant Biology, 15, 483-495.

Pretzsch H, Bielak K, Block J et al. (2013b) Productivity of mixed versus pure stands of oak (Quercus petraea (Matt.) Liebl. and Quercus robur L.) and European beech (Fagus

This article is protected by copyright. All rights reserved. 
sylvatica L.) along an ecological gradient. European Journal of Forest Research, 132, $263-280$.

R Development Core Team (2017) R: A Language and Environment for Statistical Computing.

Raftoyannis Y, Radoglou K (2002) Physiological responses of beech and sessile oak in a natural mixed stand during a dry summer. Annals of Botany, 89, 723-730.

Sánchez-Salguero R, Camarero JJ, Grau JM, de la Cruz AC, Gil PM, Minaya M, FernándezCancio Á (2017) Analysing atmospheric processes and climatic drivers of tree defoliation to determine forest vulnerability to climate warming. Forests, $\mathbf{8}, 13$.

Schwalm CR, Anderegg WRL, Michalak AM et al. (2017) Global patterns of drought recovery. Nature, 548, 202-205.

Seidl R, Rammer W, Spies TA (2014) Disturbance legacies increase the resilience of forest ecosystem structure, composition, and functioning. Ecological Applications, 24, 20632077.

Seidling W (2007) Signals of summer drought in crown condition data from the German Level I network. European Journal of Forest Research, 126, 529-544.

Tabari H, Taye MT, Willems P (2015) Water availability change in central Belgium for the late 21st century. Global and Planetary Change, 131, 115-123.

Thomas FM, Blank R, Hartmann G (2002) Abiotic and biotic factors and their interactions as causes of oak decline in Central Europe. Forest Pathology, 32, 277-307.

Tielbörger K, Kadmon R (2000) Temporal environmental variation tips the balance between facilitation and interference in desert plants. Ecology, 81, 1544-1553.

Trenberth KE, Dai A, van der Schrier G, Jones PD, Barichivich J, Briffa KR, Sheffield J (2013) Global warming and changes in drought. Nature Climate Change, 4, 17-22.

Trumbore S, Brando P, Hartmann H (2015) Forest health and global change. Science (New York, N.Y.), 349, 814-8.

Vicente-Serrano SM, Beguería S, López-Moreno JI (2010) A multiscalar drought index sensitive to global warming: The standardized precipitation evapotranspiration index.

This article is protected by copyright. All rights reserved. 
Journal of Climate, 23, 1696-1718.

Vicente-Serrano SM, Gouveia C, Camarero JJ et al. (2013) Response of vegetation to drought time-scales across global land biomes. Proceedings of the National Academy of Sciences of the United States of America, 110, 52-7.

Williams LJ, Paquette A, Cavender-Bares J, Messier C, Reich PB (2017) Spatial complementarity in tree crowns explains overyielding in species mixtures. Nature Ecology \& Evolution, 1, 63.

Zuur AF, Ieno EN, Walker N, Saveliev AA, Smith GM (2009) Mixed effects models and extensions in ecology with $R$. Springer New York, New York, NY.

\section{Figure captions}

Figure 1. Temporal pattern of defoliation of the three studied species, using 25 years of data on crown defoliation in temperate deciduous forests. Defoliation severity was expressed as the proportion (percentage $0-100 \%$, with intervals of 5\%) of leaf loss, and a mean annual value was calculated for each species. Gray dots indicate annual defoliation averaged over all trees of a monitoring plot. Solid lines represent the smoothed trend and shaded areas denote 95\% confidence intervals. $N=37,800$ observations.

Figure 2. Temporal trend of drought conditions averaged over all monitored plots according to the SPEI values. The trend shown here was calculated on a 21-month time interval for May $\left(\mathrm{SPEI}_{21-\mathrm{May}}\right)$, which corresponds to the month and the SPEI time lag at which the maximum $\mathrm{SPEI} /$ crown defoliation correlation was identified. $\mathrm{SPEI}_{21-\mathrm{May}}$ is calculated using the water balance of the 20 months prior to May and the month itself. The blue and red colors denote conditions respectively wetter or drier than the median of the 1980-2015 base period. Size of 
dots denotes the number of months per year classified as dry and the dashed line represents a loess smoother. Note that the y-axis has been reversed for convenience (i.e., negative SPEI values indicate dry conditions and positive SPEI values correspond to wet conditions).

Figure 3. Annual trends in plot-averaged tree defoliation along a tree species richness gradient in temperate deciduous forests. Defoliation severity was expressed as the proportion (percentage $0-100 \%$, with intervals of $5 \%$ ) of leaf loss. Solid lines and shaded areas represent the mean and 95\% confidence intervals for each year of the study. Positive slopes (red) indicate an increase in defoliation with increased species richness (ranging from 1 to 5), whereas negative slopes (green) denote a decrease in defoliation in more diverse stands. Nonsignificant slopes are shaded gray $(P \geq 0.05) . N=37,800$ observations.

Figure 4. Estimated interaction effects of drought and species richness on tree defoliation for each species ( $N=99$ plots). (a) Species defoliation response to drought (represented by $\mathrm{SPEI}_{21-\mathrm{May}}$ ). Shaded areas represent $95 \%$ confidence intervals (for parameter estimates, see Table 2). Negative values indicate drier than normal conditions, whereas positive values represent wetter than normal conditions. (b) Defoliation for trees growing in a monoculture or a mixed-species plot (ranging from 1 to 5 species, with plots with 4 or more species grouped into class 4), over time. The dots show the raw data points and lines the regression lines. SR is species richness.

This article is protected by copyright. All rights reserved. 
Table 1 Main characteristics of study plots. Number of observations, age class ${ }^{1}$, mean (minimum-maximum) stand basal area $^{2}$, defoliation and elevation, and mean (standard deviation) annual temperature and total annual precipitation for plots in which beech and oak trees are found. Meteorological data were averaged from daily means over the period 19902015. $N=37,800$ observations.

\begin{tabular}{lllllll}
\hline & \multicolumn{2}{l}{ Fagus sylvatica } & \multicolumn{2}{l}{ Quercus petraea } & \multicolumn{2}{l}{ Quercus robur } \\
\cline { 2 - 7 } & Pure & Mixed & Pure & Mixed & Pure & Mixed \\
\cline { 2 - 7 } Number of plots & 16 & 39 & 7 & 24 & 16 & 47 \\
Number of trees & 401 & 431 & 143 & 223 & 470 & 627 \\
Age class & $5.2(1.2)$ & $6.1(0.9)$ & $6.3(0.8)$ & $5.1(1.7)$ & $4.4(1.2)$ & $5.4(1.3)$ \\
Stand basal area $\left(\mathrm{m}^{2} \mathrm{ha}^{-1}\right)$ & $41.0(12-103)$ & $54.9(9-103)$ & $31.7(12-89)$ & $34.1(11-91)$ & $34.5(10-73)$ & $47.8(9-103)$ \\
Crown defoliation $(\%)$ & $18.4(0-95)$ & $19.8(0-100)$ & $12.0(0-100)$ & $13.3(0-80)$ & $20.9(0-100)$ & $22.2(0-100)$ \\
Elevation (m) & $287(13-568)$ & $250(10-523)$ & $306(30-446)$ & $259(4-523)$ & $113(10-426)$ & $86(4-453)$ \\
Annual temperature $\left({ }^{\circ} \mathrm{C}\right)$ & $9.4(1.1)$ & $9.7(0.9)$ & $9.2(0.8)$ & $9.5(0.8)$ & $10.4(0.8)$ & $10.5(0.6)$ \\
Annual precipitation $(\mathrm{mm})$ & $1038(145)$ & $990(120)$ & $941(92)$ & $1054(153)$ & $933(152)$ & $883(112)$ \\
\hline
\end{tabular}

${ }^{1}$ The mean age class of the dominant storey is reported in 20-year classes, as follows: ' 1 ' =0-20 years; ' 2 ' = 21-40 years; ' 3 ' $=41-60$ years; ' 4 ' $=61-80$ years; ' 5 ' = 81-100 years; ' 6 ' = 101-120 years; ' 7 ' = >120 years. Age class is unknown or could not be determined for 21 study plots.

${ }^{2}$ Tree diameter measurements (and hence basal area) were not available for 20 study plots. These plots were not included in the regression analysis.

This article is protected by copyright. All rights reserved. 
Table 2. Summary of the linear mixed-effects model to test the effects of species richness and drought over time on annual crown defoliation ${ }^{\dagger}$. Best-fit parameter estimates (Est, with standard error $s e)$, the estimated auto-regressive parameters of the $\operatorname{ARMA}(2,0)$ autocorrelation structure, the standard deviation of the random terms, and the marginal and conditional $\mathrm{R}^{2}$ are shown for $N=99$ plots.

\begin{tabular}{|c|c|c|c|}
\hline Fixed effects & Est. & se & $\boldsymbol{P}$ \\
\hline Fagus sylvatica & -206.3 & $(37.634)$ & $<0.001$ \\
\hline Quercus petraea & -117.8 & $(53.553)$ & 0.030 \\
\hline Quercus robur & -55.433 & $(30.252)$ & 0.070 \\
\hline Stand basal area & 0.006 & $(0.003)$ & 0.059 \\
\hline Age structure & 1.093 & $(0.278)$ & $<0.001$ \\
\hline Management type & 0.095 & $(0.393)$ & 0.810 \\
\hline Species Richness (SR) & 50.072 & $(17.050)$ & 0.004 \\
\hline $\mathrm{SPEI}_{21-\text { May }}$ & -0.046 & $(0.020)$ & 0.025 \\
\hline Fagus sylvatica $: \mathrm{SPEI}_{21-\mathrm{May}}$ & -0.046 & $(0.020)$ & 0.025 \\
\hline Quercus petraea : $\mathrm{SPEI}_{21-\mathrm{May}}$ & -0.035 & $(0.029)$ & 0.228 \\
\hline Quercus robur: $\mathrm{SPEI}_{21-\mathrm{May}}$ & 0.013 & $(0.016)$ & 0.442 \\
\hline Fagus sylvatica : SR : YEAR & -0.025 & $(0.009)$ & 0.003 \\
\hline Quercus petraea : SR : YEAR & -0.009 & $(0.012)$ & 0.448 \\
\hline Quercus robur : SR : YEAR & -0.001 & $(0.006)$ & 0.808 \\
\hline \multicolumn{4}{|l|}{ Random effects } \\
\hline sd plot & & 0.369 & \\
\hline sd plot cluster & & 0.369 & \\
\hline sd residuals & & 0.712 & \\
\hline \multicolumn{4}{|l|}{ Autocorrelation structure } \\
\hline ARMA $\varphi 1$ & & 0.55 & \\
\hline ARMA $\varphi 2$ & & 0.22 & \\
\hline \multicolumn{4}{|l|}{ Model statistics } \\
\hline marginal $R^{2}$ & & 0.23 & \\
\hline conditional $R^{2}$ & & 0.57 & \\
\hline
\end{tabular}

${ }^{\dagger}$ Response variable ('tree defoliation') was log-transformed prior to model fitting to normalize variance in the residuals. Drought was expressed by the SPEI (Standardized Precipitation Evapotranspiration Index) for May calculated at 21 -month lags $\left(S P E I_{21-M a y}\right)$.

This article is protected by copyright. All rights reserved. 

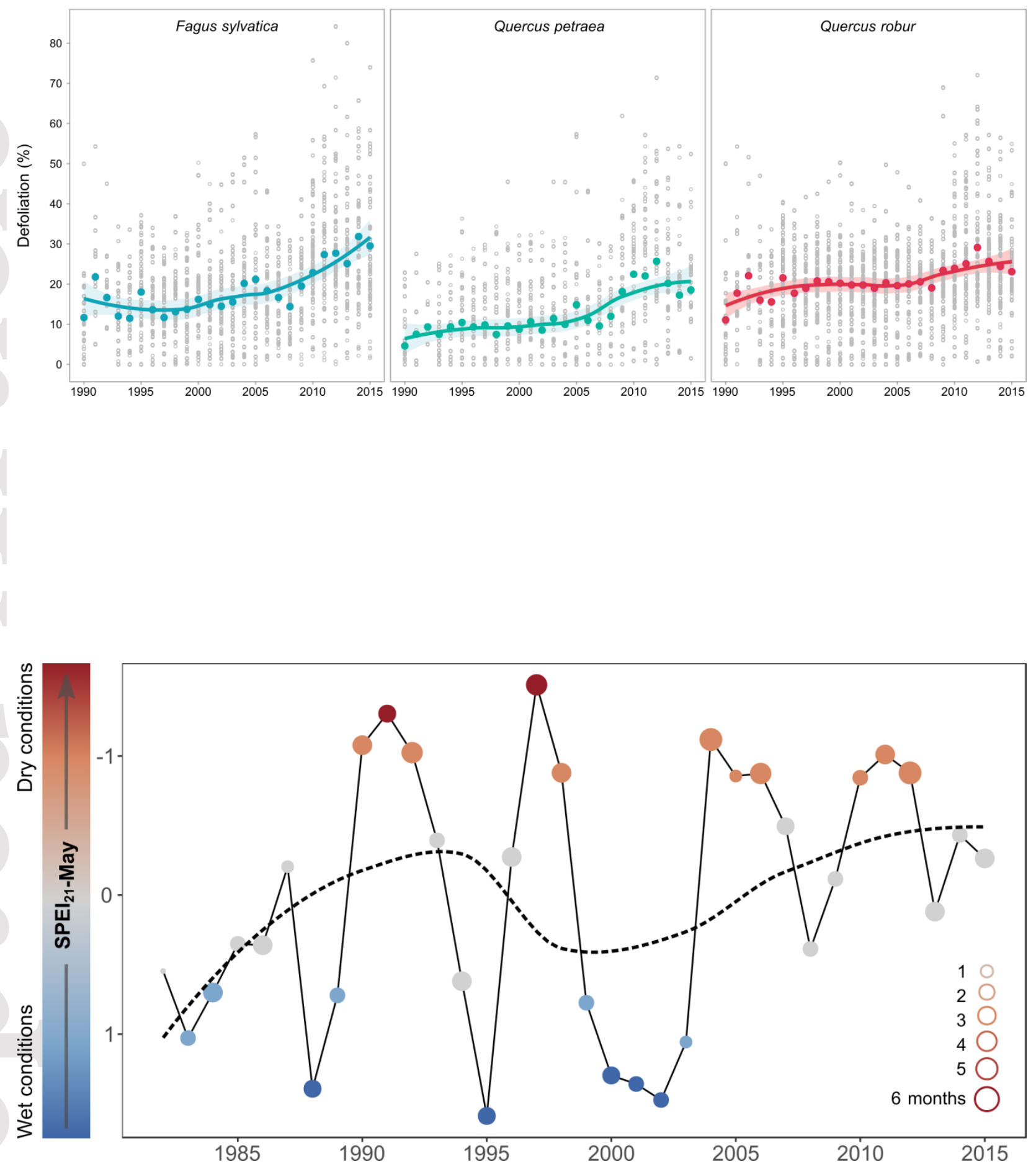

This article is protected by copyright. All rights reserved. 

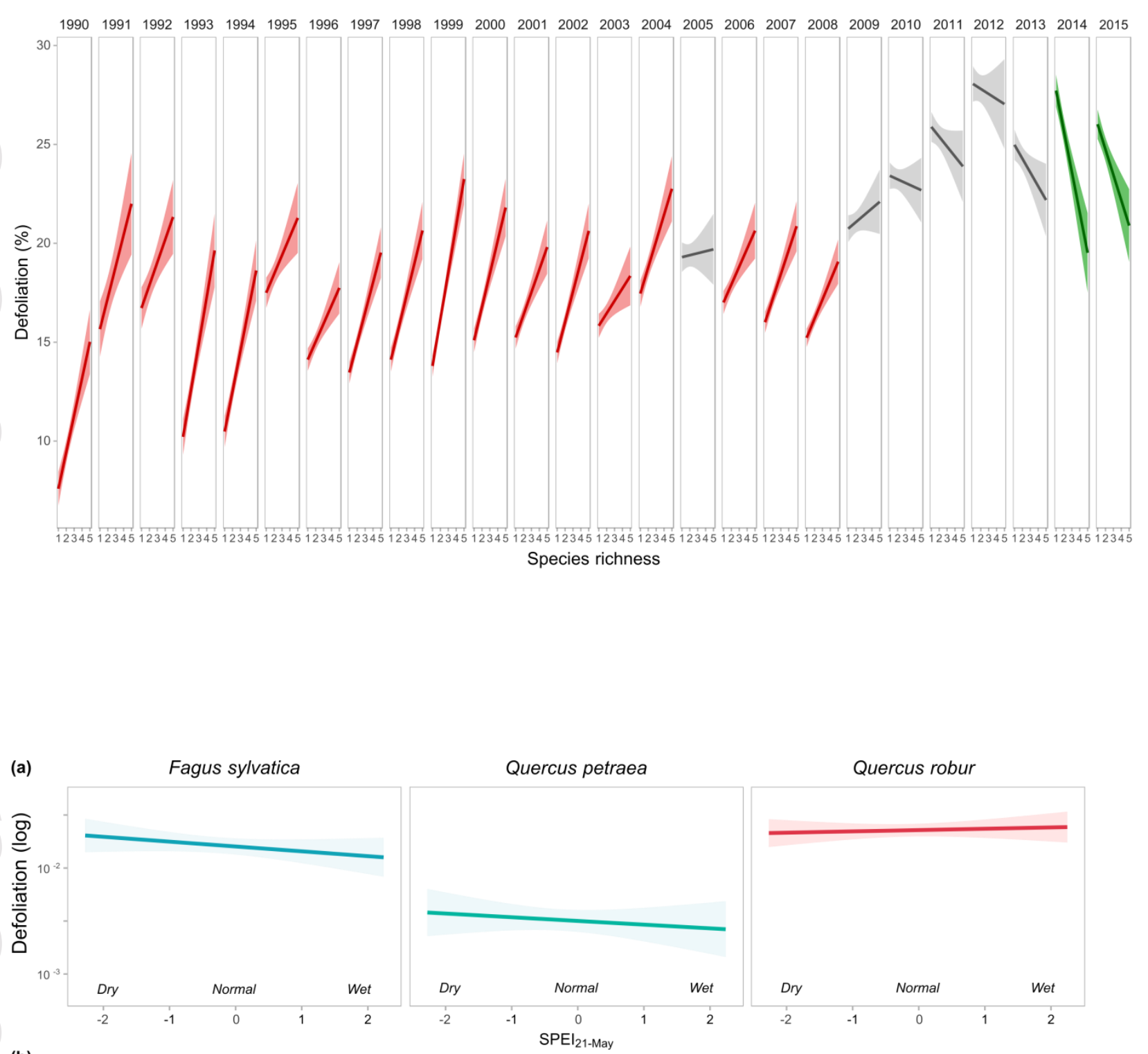

(b)

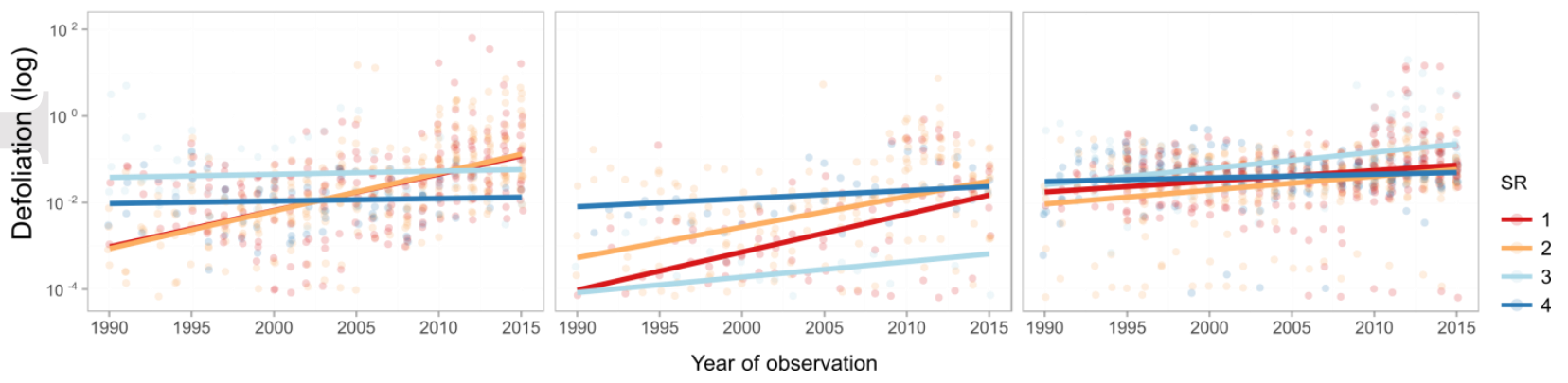

This article is protected by copyright. All rights reserved. 